\title{
CONCEITUALIZANDO PROFISSIONALIZACÃO ENTRE OS PROFESSORES DE ADULTOS NO CONTEXTO EUROPEU ${ }^{(*)}$
}

\author{
Marcella Milana \\ Oleksandra Skrypnyk ${ }^{(* *)}$
}

Cada vez mais focado no aprendizado de toda a vida, em ambos os níveis, nacional e internacional, ressurge o interesse na educação de adultos (daqui para a frente EA) como importante domínio a oferecer oportunidades intencionais para a população adulta. Muita atenção está sendo dispensada, de um lado, à criação de estruturas de oportunidade para que adultos se engajem em atividades de aprendizado intencional e, de outro lado, à profissionalização daqueles que ganham a vida garantindo a qualidade dos processos de aprendizado adulto. Esse grupo profissional é designado de maneiras diferentes como educadores de adultos, educadores de adultos profissionais (BROCKETT, 1991) e, mais recentemente, profissionais do aprendizado adulto, pelo menos no contexto europeu (COMMISSION OF THE EUROPEAN COMMUNITIES, 2007; NUISSL e LATTKE, 2008; BELEID, RESEARCH VOOR BELEID E PLATO, 2008; OSBORNE, 2009).

Entretanto, a identificação clara dos educadores de adultos profissionais é problemática no interior de várias categorizações e diversas questões precisam ser consideradas. Em primeiro lugar, desdobrar o conceito de profissionalismo na EA é uma matéria complexa devido à própria vastidão do campo e suas peculiaridades (JARVIS E ASSOCIATES, 1991; CERVERO, 1992; WILSON, 1993; MERRIAM E BROCKETT, 2007; NUISSL e LATTKE, 2008). As fronteiras que definem o status dos praticantes na EA tornam-se ainda menos nítidas quando consideramos os grupos 'ocultos' de praticantes - aqueles que ganham a vida no campo da EA mas não se identificam ou

\footnotetext{
${ }^{(*)}$ Esta contribuição já se encontra disponível em inglês, com o título "Professionals vs. Role Professionals: Conceptualising Professionalism Among Teachers of Adults" (In: Nuissl Von Rein, E. P. et al., eds., Facets of Professionalization among Adult EducationTeachers - Eurasian Perspectives, New Delhi: Sarup Book Publishers, 2015. p. 207-229) e em tcheco com o título "Konceptualizace porfesionality u vzdělavatelů dospelých" (Studia Paedagogica, v. 17, N. 1, p. 113-128, 2010).

${ }^{(* *)}$ Marcella Milana. Professora de Educação do Departamento de Ciências Humanas da Universidade de Milão. É membro da Sociedade Europeia para a pesquisa em Educação de Adultos. Seus interesses de pesquisa incluem Educação Comparada e Educação de Adultos, educação para cidadania democrática, participação na Educação de Adultos e profissionalização de educadores de adultos.

Oleksandra Skrypnyk. É doutoranda em Educação na Universidade do Sul da Austrália pesquisadora na Delf Universidade de Tecnologia na Holanda. Entre seus interesses de pesquisa de pesquisa estão: facilitação de processos de grupo em educação on-line aberta; pedagogia e aprendizagem. Tem experiência de trabalho sobre domínios do ensino de línguas, educação de adultos na tradição e integração da tecnologia nas práticas de ensino.
} 
não são identificados pelos demais como educadores de adultos. Esses grupos 'ocultos' existem devido ao número de pessoas que praticam a EA de forma irregular, ao mesmo tempo em que ganham a vida em outra parte. Em segundo lugar, identificação clara de quem é educador de adultos profissional implica o reconhecimento da contrapartida, isto é, de educadores de adultos não profissionais. Obviamente, estabelecer tais fronteiras torna-se, então, uma questão sensível: quem será incluído e quem não será? Finalmente, algumas categorias são determinadas por políticas, devido à predominante mudança de enfoque sobre o aprendizado. Porém, tomar de empréstimo o dialeto das políticas resulta numa confusão conceitual. A ação no aprendizado é atribuída ao aprendiz; na educação, ao educador. Como dizem Merriam e Brockett (2007, p. 6): “O aprendizado adulto é um processo cognitivo interno do aprendiz; é o que faz o aprendiz numa transação ensinoaprendizado, em oposição ao que faz o educador".

Se os educadores de adultos recebem ou não uma recompensa econômica, não é 'aprendizado' mas 'educação' que se encontra no cerne do serviço que proveem, o que possibilita que se fale do campo da EA ou como ocupação ou como profissão!

Tendo esse histórico como pano de fundo, é preciso que se mencione que debater sobre profissionalismo no campo da EA não configura novidade. De fato, existe uma literatura relativamente vasta sobre este tópico que, pelo menos nos Estados Unidos, data já do início dos anos 1990 (JARVIS E ASSOCIATES, 1991; CERVERO, 1992; WILSON, 1993, entre outros). No entanto, com o impulso do crescente interesse da parte dos elaboradores de políticas, da necessidade de capturar as mudanças que hoje afetam a EA e de reajustar ou redefinir/refinar suas fronteiras profissionais, debate-se atualmente uma estrutura para a compreensão do profissionalismo e do desenvolvimento profissional da EA (cf. MERRIAM e BROCKETT, 2007; NUISSL e LATTKE, 2008).

Esta contribuição tenta conceituar o profissionalismo no campo da EA com específica referência àqueles que ganham a vida ensinando para adultos. Ao fazer isso, aqui nos referimos aos profissionais da EA como categoria socioeconômica; portanto, a unidade de nossa análise será encontrada na ocupação desempenhada, ao invés de nos indivíduos que trabalham no campo da EA.

O estudo está estruturado em três partes principais. A primeira parte faz uma revisão crítica da literatura existente sobre profissionalismo. O resultado aponta que as formas tradicionais de se compreender as profissões através de generalizações estáticas não se aplicam mais; entretanto, o avanço desse campo na segunda metade do século XX ainda provê fundamento produtivo para se conceituar o profissionalismo na sociedade contemporânea. Com base nessa premissa, a seção seguinte investiga o discurso sobre profissionalização nos campos da EA. A análise destaca que 
conceituar EA como 'um' campo 'profissional', como ainda é frequentemente o caso, tem pouca utilidade quando se discute profissionalismo na EA de hoje. Consequentemente, a terceira parte do estudo revê o modelo tradicional de profissionalismo através das lentes de uma perspectiva de 'profissionalismo funcional' como tentativa de reconceituar o profissionalismo na EA. Especial atenção se dá aqui àqueles que ganham a vida ensinando para adultos. O principal argumento das autoras é que existem diversas ocupações no campo da EA. Algumas dessas ocupações são semiprofissões, sendo que poucas alcançaram status profissional pleno e outras avançam nessa direção. Porém, para que isto seja possível, poderia ser produtivo enfocar as necessidades profissionais dos praticantes da EA que desempenham papéis específicos, em vez de o tipo de ocupação que têm. A seção conclusiva discute brevemente como levar adiante essa investigação.

\section{REVISÃO DE PROFISSIONALISMO}

Semanticamente, a palavra 'profissão' - e mais tarde, suas derivadas, isto é, profissional, profissionalismo, profissionalização - tem sido usada com uma conotação mais estreita ou mais ampla dependendo dos correspondentes contextos históricos. Em sua conotação estreita, profissão está amarrada a conhecimento ou técnicas de natureza particular que podem ser adquiridos de fontes especificamente identificadas. Por mais de um século se tentou conceituar profissionalismo com base nessa interpretação. Embora as conclusões analíticas permaneçam pendentes, o campo evoluiu significativamente (CUNNIGHAM, 2008).

Nos primeiros trabalhos acadêmicos surgiram duas características para descrever o que é uma profissão, assim como a natureza altruísta do trabalho profissional dedicado ao serviço do bem público (TAWNEY, 1920) e a fundamentação teórica de conhecimento profissional (WHITEHEAD, 1933); com a última característica levantando a distinção entre conduta profissional e amadora. Enquanto a conduta profissional resulta de perícia com fundamento teórico, a conduta amadora reflete atividades costumeiras dos indivíduos refinadas por tentativa e erro (WEST, 2003).

As tentativas sistemáticas de estudar as profissões obtiveram, porém, especial ímpeto a partir da sugestão de Carr Sanders e Wilson de que "a profissão típica exibe um complexo de características" (in: WEST, 2003, p. 14). Isso levou ao desenvolvimento dos chamados modelos estáticos (CERVERO, 1988), modelos com base em traços (WEST, 2003) ou em atributos (COOK, 2008). Esses modelos identificam um conjunto de traços - às vezes um bocado numerosos - para definir uma profissão (COGAN, 1953; GREENWOOD, 1966; BARBER, 1963; WILENSKY, 1964; MILLERSON, 1964). Ainda que os conjuntos de traços variem através de países e profissões, 
estes geralmente fazem referência a: um corpo sistematizado de conhecimento central adquirido através de programas de educação superior; um guia de normas e ética, isto é, códigos de conduta; reconhecimento social e certificação e, finalmente, aspectos de organização, tais como sanções da comunidade (GREENWOOD, 1966) ou sistemas de recompensa (BARBER, 1963). As críticas a esses tipos de modelos surgiram desde o início dos anos 1970 alinhadas às mudanças históricas e expressaram-se numa mudança na maneira como as profissões e os conceitos relacionados eram estudados. O problema nos modelos estáticos, baseados em traços ou atributos, foi identificado com o fato de enfocarem o produto, ao invés do processo (ROTH, 1974, apud WEST, 2003).

Surgiram os modelos estruturais-funcionais das profissões (ELLIOTT, 1972) e a questão do poder que detinham os profissionais bem como o processo de e as razões para se adquirir esse poder foram postos no centro da cena. As ocupações profissionais, suas fontes de poder e autoridade, além das formas como se as utiliza (JOHNSON, 1972, p. 18) foram características da nova onda na maneira de ver as profissões. Esses estudos caem no rótulo depois cunhado de abordagem de processo, que descreve as formas como os profissionais exercem poder (COOK, 2008), com ênfase nas circunstâncias através das quais uma ocupação profissionaliza, no papel do Estado na formação das profissões (CERVERO, 1988) e no grau de autoridade alcançado pelas profissões dentro das organizações (ETZIONI, 1969).

Uma das principais características da nova perspectiva sobre as profissões foi a eliminação das claras fronteiras entre profissões e ocupações, dado que os processos descritos diziam respeito a cumprir os critérios que definem um campo profissional em oposição a cumprir um conjunto predefinido de características que definem uma ocupação profissional (cf. COOK, 2008). Daí que os atributos que geravam as profissões, ou seja, base de conhecimento, orientação coletiva e autonomia, foram compreendidos como um continuum, em vez de categorias fixas, fechadas (GOODE, 1969).

As tentativas sistemáticas de estudar as profissões foram acompanhadas de uma busca de padrões e sequências através dos quais os grupos ocupacionais ascendem na hierarquia ocupacional (MCDONALD, 1995) tendo como principais questões como e por que status e privilégios são adquiridos. Assim, a teoria da profissionalização surgiu como tópico situado no contexto das questões da burocratização da política (Collins, 1990). A teoria clássica da profissionalização culminou com "Professionalisation of everyone?" (Profissionalização de todo mundo?) de Wilensky (1964), que serve de linha de fronteira entre a teoria clássica da profissionalização e a onda revisionista que apareceu nos anos de 1970. De acordo com Collins (1990), o modelo de Wilensky, com sua ênfase no controle profissional do próprio treinamento e administração da 
prática, junto com a pesquisa sobre estratificação e mobilidade social, desembocou em análises históricas do processo pelo qual a educação e o credenciamento profissionais foram estabelecidos. Seguindo essa premissa, Larson (1977) conceituou a profissionalização como tentativa de traduzir uma ordem de recursos escassos - conhecimento e técnicas especiais - em uma outra ordem recompensas sociais e econômicas; daí ter ela colocado a certificação como o mecanismo central dos projetos de profissionalização.

É dentro desse período revisionista que nova atenção foi dada a profissões emergentes, assim chamadas profissões da pessoa, isto é, professores, enfermeiros, assistentes sociais, que nas sociedades em industrialização reivindicaram status profissional mais elevado. Para capturar o esforço social dessas ocupações sem quaisquer implicações depreciativas, Etzioni (1969) cunhou a expressão 'semi-profissões' assumindo que:

Seu treinamento é mais curto, seu status menos legitimado, seu direito a comunicação privilegiada, menos estabelecido; há um corpo especializado de conhecimento menor e elas têm menos autonomia em relação a supervisão ou controle da sociedade que 'as' profíssões". (ETZIONI 1969, p. 5, ênfase no original).

Sem dúvida a perspectiva sócio-histórica tem oferecido novos enfoques, tais como o fato de que as propriedades das profissões e os processos para se ganhar status mais elevados provaram ser geográfica e culturalmente contingentes. Elliot (1972), por exemplo, distingue dois tipos históricos de profissões representativas de vários países europeus: as profissões de status, relativamente sem importância na organização do trabalho e serviços da comunidade mas que ocupam um nicho elevado nos sistemas de estratificação social e as profissões ocupacionais, baseadas em especialização do conhecimento e das tarefas.

Siegrist (2004) sugere que as particularidades sociais do sentido que é colocado em 'profissão' e conceitos relacionados podem em última instância ser rastreados retrospectivamente até à gênese, formação e duração de determinados sistemas políticos e sociais. Mais especificamente, argumenta que os processos de profissionalização estão presos ao contexto introduzido durante o processo de disciplinar a sociedade. Isto pode elucidar a divisão entre modelos anglo-saxônicos e continentais observada por Collins (1990), com o primeiro modelo realçando a liberdade dos praticantes auto-empregados de controlar as condições de trabalho e o último modelo realçando a posse de escritórios por administradores de elite em virtude das credenciais acadêmicas. Deve-se notar, porém, que ambos os modelos referem-se a ocupações que se organizam horizontalmente, como comunidades com um certo estilo de vida, código de ética, auto-consciência de sua identidade e barreiras para forasteiros; daí que, em certa medida, elas transcenderam especificidades dos Estados-nações. As tensões existentes entre especificidades de 
Estados-nações e processos ligados ao contexto de disciplina social que vão além de fronteiras geográficas podem em parte ser explicadas à luz do fato de que “(...) diante da liberalização do mercado europeu, do surgimento da União Europeia e da globalização... [a] dimensão nacional se torna mais fraca" (SIEGRIST 2004, p. 82).

Esta breve recapitulação da literatura sobre profissionalismo mostra como o campo é fragmentado e apresenta visões e abordagens divergentes para a compreensão das profissões. Entretanto, no mar de opções entre modelos de atributos versus modelos de processos, bem como métodos que propõem ver-se profissões e conceitos relacionados através de prisma histórico ou tentar generalizações, parece razoável concluir, tomando emprestadas as palavras de Crompton (1987, p. 106): “o profissionalismo não é inevitável, nem universal, nem de qualquer tipo único". A partir desta premissa, vamos agora voltar nossa atenção para o atual debate sobre profissionalismo dentro do domínio da EA.

\section{PROFISSIONALISMO NA EDUCAÇÃO DE ADULTOS HOJE}

A literatura sobre profissionalismo na EA não é tão extensa e é bem mais fragmentada quando comparada à literatura existente sobre o profissionalismo como tal, e o trabalho acadêmico sobre profissionalismo na corrente principal da educação (cf. CUNNINGHAM, 2008; EVANS 2008; KINOS, 2008; THOMPSON, 2009) ou entre professores de escola (cf. BECK, 2009; HARGREAVES, 2000; HUMPHREYS, 2002; VOLKMANN, ANDERSON, 1998; WHITTY, 2008). A maior parte da literatura sobre profissionalização na EA se preocupa principalmente com relatos descritivos e/ou analíticos do campo no qual as pessoas ganham a vida como educadores de adultos e processos de profissionalização em curso em diferentes países (cf. EUROPEAN JOURNAL OF EDUCATION, 2009). Estes incluem as análises de vias existentes na educação e treinamento para (candidatos a) educadores de adultos (MILANA, 2009) e a avaliação de programas especializados de estudo (KASWORM, HEMMINGSEN, 2007) entre outros. Em suma, a literatura disponível trata do profissionalismo mais em termos de condições de trabalho e regulamentações que afetam educadores de adultos. Daí que o profissionalismo no campo é tido como um ponto pacífico ao qual se faz referência frequente, mas que raramente se define e/ou questiona. Este fenômeno observado pode ser em parte explicado pelo fato de que a EA enquanto campo ocupacional está frequentemente conectada com outros setores ou ocupações, ou seja, a corrente principal da educação, o desenvolvimento da comunidade, o trabalho social. Consequentemente, discutir profissionalismo em toda a extensão do campo da EA requereria levar em consideração seu desenvolvimento histórico e atual. Embora isto ultrapasse o escopo da 
presente contribuição, acreditamos que é possível tocar brevemente no debate em andamento sobre o profissional na EA.

É difícil aplicar categorias idênticas para descrever vários grupos ocupacionais empregados na EA em diferentes países e/ou regiões do mundo. Essa dificuldade é resultado direto da questão mencionada anteriormente: falta de claras fronteiras em torno dos grupos profissionais que praticam EA. Nos Estados Unidos, se o campo é visto em sua extensão total, é fácil argumentar que aqueles que ganham a vida trabalhando exclusivamente em instituição de EA são apenas uma minoria. $\mathrm{O}$ processo de institucionalização no campo da EA (CUNNINGHAM, 1991, apud MERRIAM, BROCKETT, 2007, p. 87) e o surgimento da EA 'instrumental' (DESHLER,1991) contribuem para a visibilidade daquelas ocupações que estão envolvidas com a produção de EA formalizada, organizada, em detrimento de outras ocupações, que se tornam invisíveis. Como apontam Merriam, Brockett (2007), o resultado da institucionalização da EA foi subjugar a EA à crescente orientação de mercado que caracteriza hoje a corrente principal da educação nos EUA. Com referência ao contexto europeu, Lattke, Nuissl (2008) de modo similar ressaltam como as práticas de EA são legitimadas não apenas por empregados em tempo integral mas também por grupos (ocupacionais) 'ocultos'. Ironicamente, a variedade de agentes no interior da EA é um dos traços comuns, enquanto o campo da prática como tal é caracterizado por um alto grau de desregulamentação e diversidade de estruturas, de provisão de aprendizado e atores em todo o mundo (cf. RESEARCH VOOR BELEID, 2008; CARUSO et al., 2008).

Para evitar a aplicação de categorias idênticas a grupos ocupacionais que praticam EA, tentativas recentes de conceituar o profissionalismo no campo fazem referência a campos de atividade ou funções que as pessoas desempenham para possibilitar e dar suporte ao aprendizado de adultos, em vez de a perfis ocupacionais (NUISSL, LATTKE, 2008). Esta é uma abordagem produtiva na medida em que, de maneira similar à da abordagem de processo, quebra as fronteiras entre ocupações diferentes ao descrever os processos envolvidos no desempenho de uma atividade educacional, ao invés de contextos específicos no interior dos quais essa atividade ocorre. No entanto, tal abordagem também contém algumas armadilhas. Por exemplo, descrever um número seleto de atividades continua a produzir uma categorização fechada que, longe de exaustiva, é geográfica e culturalmente contingente. Além do mais, a conceituação do profissionalismo na EA de acordo com os campos de atividade ou funções desempenhadas não nos liberta do impasse revelado por todo um século de estudos sobre profissionalismo: certas funções são tratadas diferentemente nos vários contextos sociais. 
De maneira similar, abordar a profissionalização dentro da EA através de diferentes aspectos que demonstram profissionalismo avançado (CERVERO, 1992) não resistiria à crítica dos seguidores da abordagem do processo para estudar profissões. Partindo da crença em que 'a intenção da profissionalização é melhorar a prática', Merriam, Brockett (2007) argumentam que a profissionalização no campo da EA é uma realidade, pelo menos nos EUA. Para dar apoio ao argumento, tocam nos programas de pós-graduação que proveem estudos avançados no campo de EA, na literatura e fontes de informação existentes que permitem aos praticantes de EA rever criticamente suas práticas e nas associações profissionais que socializam os 'recém-chegados' bem como garantem o desenvolvimento profissional. Essa análise certamente tem valor, pois também considera temas críticos em conexão com cada um dos aspectos em foco. Em primeiro lugar, reconhece que os focos refletem principalmente o avanço profissional no campo da EA formal, institucionalizada. Em segundo lugar, os estudos de pós-graduação, embora úteis para definir um campo de ação, correm o risco de reforçar a divisão entre a corrente principal da EA e outros lados 'invisíveis' do campo. Então, a literatura e as fontes de informação existentes ainda privilegiam o conhecimento codificado e/ou o conhecimento disciplinar versus o conhecimento menos codificado e o conhecimento informal ao garantir a melhoria da prática. Por último, mas não menos importante, as associações profissionais, apesar de importantes agências socializadoras, correm o risco de criar círculos elitistas, especialmente naqueles casos onde são poucos os membros.

Pode-se ver que a análise de Merriam, Brockett está estruturada dentro da definição tradicional de uma profissão com ênfase nos traços: treinamento especial num nível mais elevado (isto é, cursos de pós-graduação); base de conhecimento especializado (isto é, literatura e fontes de informação) e participação numa comunidade profissional que reforça um senso de pertencimento e, a partir daí, uma identidade profissional (isto é, associações profissionais). Além disso, mesmo dentro de tal abordagem, não seria por demais simplista considerar a intenção de profissionalização como uma melhoria da prática? O que deveria, então, ser feito a respeito das ocupações que lidam com o bem-estar psicofísico de uma pessoa, geralmente agrupadas sob a categoria de medicina alternativa, por exemplo, fitoterapia, acupuntura, magnoterapia? O mais provável é que essas ocupações estejam também mirando melhorar a prática, mas apesar de serem consideradas profissões no contexto asiático, enfrentam dificuldades para receber o mesmo tipo de reconhecimento em outras partes do globo, independentemente da provisão de cursos especializados, existência de literatura e fontes de informação especializadas e associações especializadas. Ao contrário, Bron, Jarvis (2008) se distanciam dessa posição reconhecendo que absolutamente não é possível falar de praticantes de EA como representantes de uma profissão no 
sentido tradicional. Olhando as estruturas contemporâneas de ocupação que se veem como profissão, os autores não tratam a EA como uma ocupação unificada. Citando a distinção de Elliott (1972) entre profissões ocupacionais e profissões de status, Bron, Jarvis sugerem que os educadores de adultos deveriam ser designados profissionais funcionais. Isto possibilita reconhecer alguma unidade dentro de diferentes grupos ocupacionais empregados no campo da EA com referência à função ou papel que eles desempenham, ainda que possam não representar um grupo unido quando se considera sua ocupação específica. É preciso notar, porém, que a distinção de Elliott (1972) emergiu de uma análise sociológica que, com o surgimento dos modelos estruturais-funcionais das profissões, voltou-se principalmente para a função do poder detido por certos grupos ocupacionais na sociedade. Diferentemente a linha de argumentação de Bron, Jarvis's (2008), tem como ponto de partida a linguagem, que é interpretada como um elemento temporário e ligado ao tempo, que expõe o pensamento das pessoas; daí que a linguagem constitui o elemento central para a identificação com uma comunidade em particular, isto é, grupo social, tal como uma comunidade profissional. Seguindo esse raciocínio, os autores concluem que:

(...) sem mudar de identidade ou adquirir uma nova é impossível tornar-se um profissional numa profissão específica... No que diz respeito à mudança de identidade dos educadores de adultos, nossa hipótese é que hoje em dia os educadores de adultos pertencem a grupos diferentes dentro dos quais eles desenvolvem suas identidades. (BRON, JARVIS, 2008, p. 40).

Em outras palavras, os educadores de adultos desenvolvem identidades múltiplas em conexão com seu campo disciplinar de estudo, por exemplo linguística, sociologia, psicologia; sua ocupação no momento, por exemplo consultor, gerente, professor e EA como campo de prática (profissional). Essa conceituação distingue entre diversas ocupações no interior de um campo comum de prática; no entanto, ela ainda apresenta algumas ambiguidades, posto que não define profissionalismo na EA. Tratamos desse tema na seção seguinte, revisitando a abordagem de processo do profissionalismo.

Investigando o profissionalismo funcional entre professores de adultos para ilustrar a ambiguidade que permeia a perspectiva do profissionalismo funcional, examinemos diferentes ocupações de pessoas que ganham a vida dando suporte ao aprendizado adulto num contexto organizacional, isto é, uma instituição de ensino superior. A instituição é fornecedora de programas de mestrado dirigidos a praticantes que desejam retornar à universidade com o fim de adquirir mais qualificação. Os programas são criados, gerenciados e implementados por um grupo de pessoas composto, entre outras, por: um catedrático de EA, que pesquisa o campo e contribui para a criação e implementação do programa; uma pessoa contratada com o único propósito de ensinar algo de tópicos específicos; uma pessoa da administração, que aceita/rejeita as inscrições de pretendentes a 
estudantes. Aplicando a perspectiva do profissionalismo funcional, conforme apresentada anteriormente, o catedrático, o professor e o funcionário administrativo, apesar das diferenças quanto aos seus campos disciplinares de estudo e ocupação corrente, estão conectados a, compartilham, pelo menos uma das suas múltiplas identidades: eles são profissionais de um campo de prática comum. Claramente, devido à vastidão do campo da EA, tratar das funções que os praticantes desempenham resolve parte do problema da compreensão do profissionalismo. Entretanto, um aspecto importante fica sem atenção dentro de tal entendimento do profissionalismo: o conhecimento que esses profissionais possuem, o serviço ideal que desempenham e o grau de autonomia que detêm não são os mesmos.

Fig. 1 - Ocupaçőes, profissőes e semi-profissőes

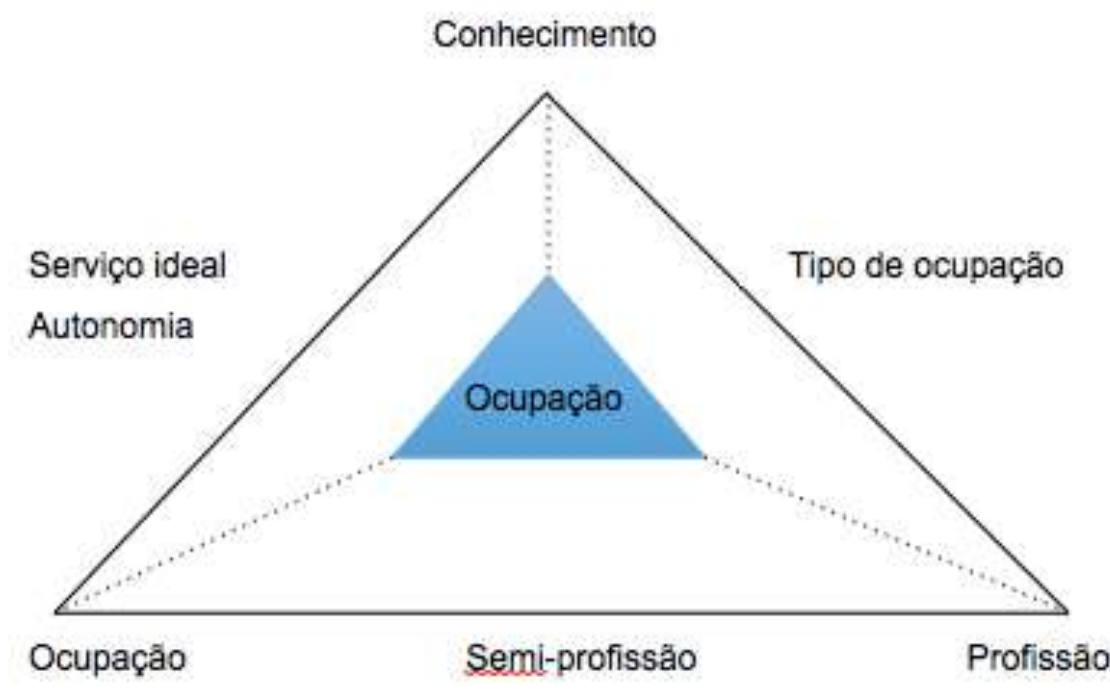

Fonte: Goode. J.W. The theacatical limits of professianalisation. [Os limites teóricos da profissionalizaçāo]. In: Etzioni, A. (ed.), The semi-pmofessions and their organjzation. [As seçiprofissōes e sua organizaçăo], 1969. pp. 266-313.

O conhecimento profissional, o serviço ideal e a autonomia representam três qualidades geradoras de uma profissão (GOODE, 1969), como ilustra a Figura $1 .^{(*)}$ Consequentemente, para tratar da questão da possibilidade de comparação entre os praticantes da EA em pauta no nosso exemplo, bem como para estabelecer as fronteiras para identificação da EA enquanto campo comum de sua prática, é necessário internalizar os pontos de vista desenvolvidos na abordagem tradicional das profissões. Goode (1969) caracteriza o conhecimento profissional como um corpo de

\footnotetext{
${ }^{(*)}$ Reprodução fac-símile.
} 
princípios codificados aplicáveis aos problemas concretos do viver, isto é, conhecimento abstrato e organizado que tem um potencial para ação. É inquestionável que a EA herdou pedagogia como o cerne de seu corpo de conhecimento profissional. Além do mais, há um sólido volume de informação acadêmica enraizada na psicologia educacional que descreve as formas como os adultos pensam, processam e abordam novas informações e, o mais importante, como eles são motivados a se engajar em processos de aprendizado. Com o tempo, essa base de conhecimento foi sendo complementada por literatura acadêmica valendo-se da sociologia educacional, que descreve o contexto social em que os adultos vivem, trabalham e aprendem. Isso resulta no que é conhecido como teorias do aprendizado adulto, que levam em consideração as dimensões pessoais bem como as sociais do aprendizado e, consequentemente, métodos apropriados de se trabalhar com adultos em cenários educacionais. Ao mesmo tempo, os praticantes de EA recebem verba para pesquisa, formam redes para fazer avançar o corpo de conhecimento relacionado a como os adultos aprendem e como seus processos deveriam ser facilitados. Além do mais, o discurso das políticas parece dispensar mais poder e reconhecimento à ES, embora exames críticos também apontem a estreiteza de uma empresa educacional "que ignora os custos sociais da transformação em mercadoria de bens materiais para seres humanos" (CUNNIGHMAN, 2000, p. 573). O serviço ideal é outra qualidade que Goode atribui ao profissionalismo, assim descrito:

a norma pela qual as soluções técnicas a que o profissional chega deveriam se basear na necessidade do cliente, não necessariamente no melhor interesse material ou necessidade do próprio profissional, e nem, aliás, nos da sociedade. (GOODE, 1969, p. 278).

É indiscutível que os praticantes da EA prestam serviço a indivíduos aprendizes, que contribuem para a criação de seres humanos enquanto partícipes ativos na sociedade; por essa razão, os praticantes da EA desempenharam historicamente um papel único ao facilitar a participação dos cidadãos em diferentes esferas da vida. A função deles hoje não diminuiu. Pelo contrário, o alto grau de complexidade que caracteriza a sociedade moderna reforça a centralidade do serviço que proveem os praticantes da EJA. Hoje, no entanto, a administração, a criação e a entrega do serviço de EJA, incorpora valores ambíguos. De um lado, provê aos indivíduos estímulos enriquecedores que contribuem para a construção de suas vidas. De outro, é uma mercadoria através da qual provedores de educação buscam lucro pessoal e um meio de controlar o tipo de conhecimento adquirido pelos adultos (JARVIS, 2009). Consequentemente, o foco de Goode no serviço ideal, meio século mais tarde, ainda é relevante, já que tem importantes implicações éticas. 
Finalmente, é o compromisso com o serviço ideal em combinação com o domínio do campo de conhecimento que gera, de acordo com Goode (1969), a terceira qualidade que profissionaliza uma ocupação: autonomia profissional. Quanto mais alto o grau de autonomia e confiança dispensadas a uma profissão pela sociedade em geral, organizações e clientes, mais status profissional tem a ocupação. É inegável, como se ressaltou na seção anterior, que o alto grau de desregulamentação e diversidade de estruturas, provisão de aprendizado e atores que opera no campo da EA tem importantes implicações no grau de autonomia que se dá aos praticantes de EA. O conhecimento, o serviço ideal e a autonomia, entretanto, são entendidos por Goode (1969) sempre em uma relação dependente, que constitui um continuum ao longo do qual diversos posicionamentos são possíveis. Daí, aplicando a interpretação de Goode ao exemplo dado no início desta seção, num dos extremos do continuum profissional encontram-se aquelas ocupações que não alcançam status profissional, isto é, as funções administrativas. Essas ocupações implicam um corpo limitado de conhecimento abstrato; servem exclusivamente a clientes corporativos e têm oportunidades limitadas de comportamento autônomo. No extremo oposto do continuum, estão as ocupações totalmente reconhecidas isto é, o professor catedrático, que possui um extenso corpo de conhecimento abstrato e codificado; serve ao indivíduo como cliente principal e possui um alto grau de autonomia. Em algum ponto entre essas duas posições, está o que Etzioni (1969) chama de semiprofissionais, isto é, o professor, que possui um certo grau de conhecimento abstrato, serve ao cliente individual, embora frequentemente para o benefício final do cliente corporativo e tem certo grau de autonomia, mas não necessariamente, fora da sala de aula. Resumindo, embora o funcionário administrativo, o catedrático e o professor trabalhem dentro do mesmo campo, ou seja, a EA, seu status profissional é diferente.

Seguindo a linha desse argumento, ensinar a adultos, enquanto campo de ocupação no sentido mais amplo, ainda representa uma semiprofissão. Na maior parte dos casos, de fato, os requisitos de entrada nessa ocupação incluem um conhecimento certificado da matéria a ser ensinada, raramente combinado com conhecimento certificado de pedagogia e/ou métodos de ensino, mas não necessariamente conhecimento de teorias e práticas de aprendizado de adultos. $\mathrm{O}$ serviço ideal desses praticantes pode variar substancialmente, dependendo do campo específico de prática em que estarão entrando, isto é, programa de EA correspondente a um ciclo de educação curto, médio ou longo. Entretanto, acontece frequentemente dos professores servirem em primeiro lugar e principalmente ao cliente corporativo que paga seus salários, tanto em instituições educacionais públicas como em companhias particulares. O grau de autonomia que eles possuem também varia substancialmente, dependendo de suas obrigações contratuais bem como do contexto 
específico da prática em que desempenham seu trabalho. Reexaminando o continuum de Goode à luz da perspectiva do profissionalismo funcional, porém, sugerimos que é possível estudar a posição dos praticantes de EA no continuum profissional fazendo referência às funções que eles desempenham, conforme ilustrado na Figura $2 .^{(*)}$

Fig. 2. Combinaçâo das perspectivas tradicionais e do profissionalismo funcional

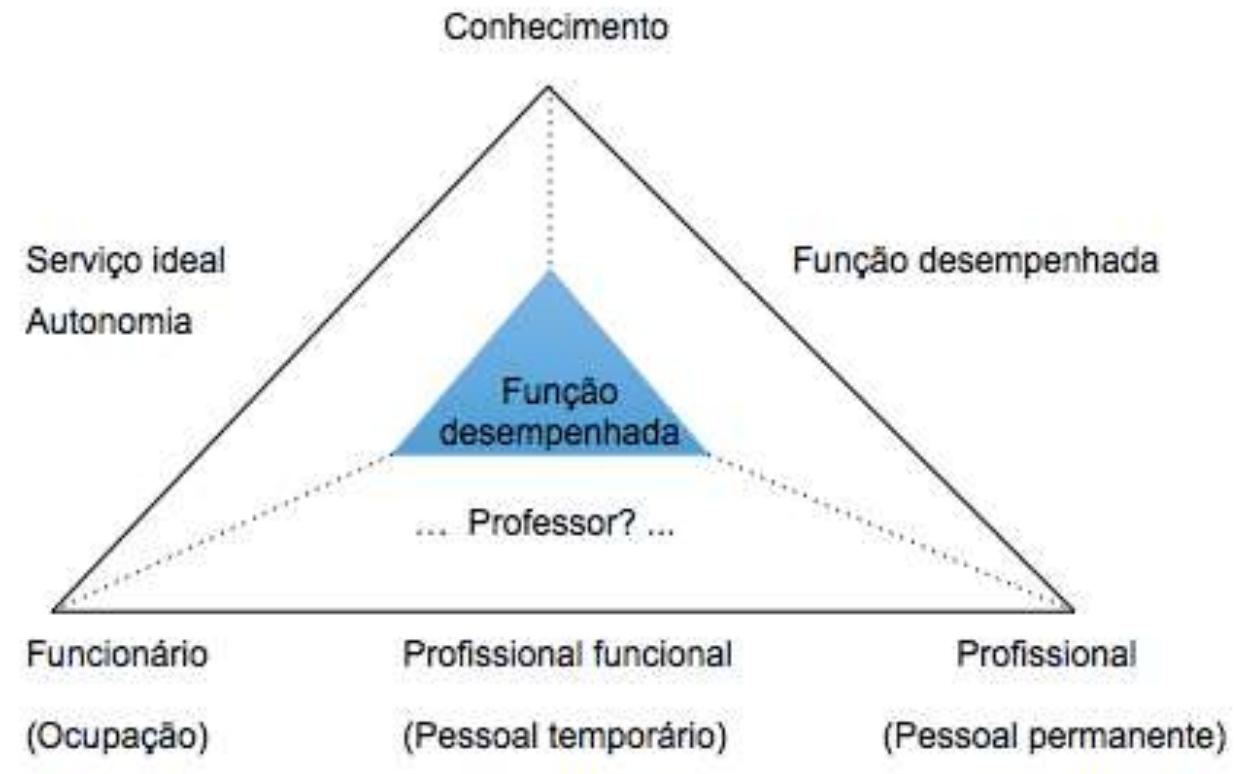

Voltando ao exemplo dado no início desta seção, três funções podem ser identificadas: administrador de curso, criador de curso e professor. Cada função desempenhada pode implicar um grau 'mais alto' ou 'mais baixo' de 'profissionalismo' que não combina necessariamente com o grau de profissionalismo reconhecido para a ocupação correspondente. É preciso que se tenha em mente, porém, que as funções diferentes que os praticantes de EA desempenham também possuem inegáveis características intrínsecas. Em primeiro lugar, cada função requer uma certa base de conhecimento em termos de quantidade e qualidade, isto é, conhecimento abstrato versus prático, produção versus aplicação de conhecimento. Em segundo lugar, cada função provê um tipo específico de serviço a ambos, clientes pessoais e corporativos, ou seja, indivíduos, organizações e a sociedade em geral. Em terceiro lugar, cada função implica um certo grau de autonomia em seu desempenho bem como no contexto da organização em que é desempenhada.

\footnotetext{
${ }^{(*)}$ Reprodução fac-símile.
} 
Ao aplicar este ponto de vista àqueles que ensinam a adultos, independentemente da tipologia da ocupação que têm, é preciso se levar em conta que alguns professores têm, em termos dos padrões profissionais, desempenho mais elevado que outros. Isso é resultado dos diferentes graus de conhecimento codificado que possuem, do tipo diferente de serviço que proveem aos aprendizes e do grau diferente de autonomia. Além do mais, deve-se considerar que eles podem agir de acordo com diferentes normas e valores éticos, frequentemente representando uma combinação de valores legais, valores da profissão, valores de profissionais individuais e valores das organizações empregadoras (ERAUT, 1994, apud LUNT, 2008). As diversidades existentes no grau de profissionalismo em meio aos professores de adultos é muitas vezes resultado de processos de profissionalização individuais, ao invés de corporativos. Daí que, embora os indivíduos se profissionalizem, isso pode não acontecer com as suas ocupações! Reconhecer o status atual do profissionalismo do professor de adultos como profissional funcional tem importantes implicações para (re)pensar ambos, educação e treinamento pré-serviço e em-serviço.

\section{CONCLUSÕES}

O principal argumento que apresentamos neste trabalho é que não é apropriado conceituar a AE como uma profissão ou como um campo profissional tout court. Existem diversas ocupações no campo da EA que se posicionam ao longo de um continuum. Só poucas alcançaram status profissional pleno, enquanto outras podem avançar nessa direção, tais como aquelas que já se encontram em posição de semi-profissionalismo. Entre essas, identificamos muitos professores de adultos trabalhando em diferentes contextos organizacionais. Para que as ocupações e semiprofissões avancem ao longo do continuum na direção do profissionalismo pleno, colocamos a necessidade de se re-conceituar o profissionalismo entre os praticantes da EA. Nossa tentativa de revisitar a abordagem tradicional ao profissionalismo, ou seja, o modelo de processos, pelas lentes de uma perspectiva de profissionalismo funcional, vai nessa direção. Em particular, sugerimos que a profissionalização no campo da EA seja avaliada à luz do conhecimento das teorias do aprendizado adulto que os praticantes possuem, da epistemologia ética que guia seu comportamento e do grau de confiança dos aprendizes adultos, ao invés de em vista da ocupação específica que têm. Como resultado, consideramos a necessidade de levar adiante esta investigação reconhecendo a importância que assume uma função específica, de um lado para aquele que a desempenha se identificar com um grupo (profissional) e, de outro lado, para o grupo (profissional) refletir sobre as relações existentes entre o conhecimento que requer, o serviço que provê e a autonomia que permite dentro de um contexto organizacional específico. O reconhecimento de que várias funções têm 
vários graus de aplicação de conhecimento, autonomia e possivelmente normas éticas diferentes tem importantes implicações para o desenvolvimento profissional em geral e para a educação e o treinamento pré-serviço e em-serviço em particular.

\section{REFERÊNCIAS}

BARBER, B. Some problems in the sociology of professions. Daedalus, v. 92, n. 4, p. 669-688, 1963.

BECK, J. Appropriating professionalism: restructuring the official knowledge base of England's 'modernised' teaching profession. British Journal of Sociology of Education, v. 30, n.1, p. 3-14, 2009.

RESEARCH VOOR BELEID; PLATO. Alpine. Adult Learning Professionals in Europe. A study of the current situation, trends and issues. Final report. Zoetemer, 2008.

BROCKETT, R.G. Professional development, artistry, and style. New Directions for Adult and Continuing Education, V. 51, p. 5-13, 1991.

BRON, A.; JARVIS, P. Identities of adult educators: changes in professionality. In: NUISSL, E.; LATTKE, S. (Eds.). Qualifying adult learning professionals in Europe. Bielefeld: W. Bertelsmann Verlag, 2008. p. 33-44.

CARUSO, A. et al. Situacíon presente de la education de personas jóvenes y adultas en América Latina y el Caraibe. Pátzcuaro, Mexico: CEAAL, 2008.

CERVERO, R. M. Effective Continuing Education for Professionals. San Francisco: Jossey-Bass, 1988.

(1992). Adult and continuing education should strive for professionalisation. In: GALBRAITH M. G.; SISCO, B. (Eds.). Confronting controversies in challenging times: A call for action. San Francisco: Jossey-Bass. vol. 54, p. 45-50.

COGAN, M.L. Toward a definition of profession. Harvard Educational Review, v. 23, n. 1, p. 33-50, 1953.

COLLINS, R. Changing conceptions in the sociology of the professions. In: TORSTENDAHL, R.; BURRAGE, M. (Ed.). The Formation of Professions: Knowledge, State and Strategy, London, Sage, 1990. p. 11-23.

COMMISSION OF THE EUROPEAN COMMUNITIES. Communication from the Commission - Adult learning: It is never too late to learn, 2007.

COOK, D. Some historical perspectives on professionalism. In: CUNNINGHAM, B. (Ed.). Exploring professionalism. London: Bedford Wall Papers, 2008. p. 10-27.

CROMPTON, R. Gender and accountancy: a response to Tinker and Neimark. Accounting, organizations and society, v. 12, n. 1, p. 103-110, 1987.

CUNNINGHAM, B. (Ed.). Exploring professionalism. London: Bedford Way Papers, 2008.

(2000). A sociology of adult education. In: WILSON, A.; HAYES, E. (Eds.). Handbook of Adult and Continuing Education. San-Francisco: Jossey-Bass, 2000. p. 573-590.

DESHLER, D. (1991). Social, professional, and academic issues. In: PETERS, J. M.; JARVIS, P. (Eds.). Adult education: Evolution and achievements in a developing field of study. San Francisco: Jossey-Bass, 1991. p. 384-420.

ELLIOTT, P. The Sociology of Professions. London: Macmillan, 1972.

. (Ed.). The semi-professions and their organization. London: The Free Press, 1969.

EUROPEAN JOURNAL OF EDUCATION. Special issue, The Training of AE Professionals, v. 44, n. $2,2009$.

EVANS, L. Professionalism, professionality and the development of education professionals. British Journal of Educational Studies, v. 56, n. 1, p. 20-38, 2008.

GOODE, J. W. The theorethical limits of professionalisation. In: ETZIONI, A. (Ed.), The semi-professions and their organization. London: The Free Press, 1969. p. 266-313.

GREENWOOD, E. Attributes of a profession. In: VOLLMER, H. M.; MILLS, D.L. (Eds.) Professionalization. Englewood Cliffs: Prentice-Hall, 1966. p. 9-19. 
HARGREAVES, A. Four Ages of Professionalism and Professional Learning. Teachers and teaching: theory and practice, v. 6, n. 2, p. 151-182, 2000.

HOYLE, E. Professionality, Professionalism and Control in Teaching. In: HOUGHTON, V. et al. (Eds.). Management in Education: The Management of Organisations and Individuals. London: Ward Lock Educational in Association with Open University Press, 1975. p. 314-320.

HUMPHREYS, M. Theory, Practice and Performance in Teaching: professionalism, intuition, and jazz. Educational Studies, v. 28, n. 1, p. 5-15, 2002.

JARVIS, P.; PETERS, J. M.; ASSOCIATES. Adult education: evolution and achievements in a developing field of study. San Francisco: Jossey-Bass, 1991.

JARVIS, P. (ed.). The Routledge Internaltional Handbook of Lifelong Learning. New York: Routledge, 2009.

JOHNSON, P. Professions and Power. London: Macmillan, 1972.

KASWORM, C.; HEMMINGSEN, L. Preparing professionals for lifelong learning: Comparative examination of master's education programs. Higher education, v. 54, n. 3, p. 449-468, 2007.

KINOS, J. Professionalism - a breeding ground for struggle. The example of the Finnish day-care centre. European Early Childhood Education Research Journal, v. 16, n. 2, p. 224-241, 2008.

LARSON, M.S. The Rise of Professionalism: a Sociological Analysis. Berkley: University of California Press, 1977.

LUNT, I. Ethical issues in professional life. In: CUNNINGHAM, B. (Ed.), Exploring professionalism. London: Bedford Way Papers. p. 73-98.

MACDONALD, K.M. The Sociology of Professions. London: Sage, 1995.

MERRIAM, S. B.; Brockett, R. G. The Profession and Practice of Adult Education: An introduction. 2. ed. San Francisco: John Wiley \& Sons, 2007.

MILANA, M. Initial education and training pathways for Danish adult educators. In: Journal of Educational Sciences, v. XI, n. 1 (19), p. 95-102, 2009.

MILlERSON, G. The Qualifying Associations: A Study in Professionalization. London: Routledge and Kegan Paul, 1964.

NUISSL, E.; LATTKE, S. (Eds.). Qualifying adult learning professionals in Europe. Bielefeld: W. Bertelsmann Verlag, 2008.

OSBORNE, M. Editorial. Adult Learning Professionals in Europe European Journal of Education. Special Issue: The Training of Adult Education Professionals in Europe, v. 44, n. 2, p. 143-144, 2009.

SIEGRIST, H. The Professions in Nineteenth-Century Europe. In: KAEBLE, H. (ed.), The European Way. European societies during the nineteenth and twentieth centuries. New York and Oxford: Berghahn Books, 2004. p. 68-89.

TAWNEY, R.H. The Acquisitive Society. New York: Harcourt, Brace and Company, 1920.

THOMPSON, M. Professionalism and professional development. Professional Development in Education, v. 35, n. 2 , p. $169-174,2009$.

VOLKMANN, M. J.; ANDERSON, M. A. Creating professional identity: Dilemmas and metaphors of a first year chemistry teacher. Science Education, v. 82, p. 293-310, 1998.

WEST, B. P. Professionalism and Accounting Rules. London and New York: Routledge, 2003.

WHITEHEAD, A.N. Adventures of Ideas. Cambridge: Cambridge University Press, 1993.

WHITTY, G. Changing modes of teacher professionalism: traditional, managerial, collaborative and democratic. In: CUNNINGHAM, B. (Ed.). Exploring professionalism. London: Bedford Way Papers, 2008. p. 28-49.

WILENSKY, H. The Professionalization of Everyone? The American Journal of Sociology, v. LXX, n. 2, p. 137-158, 1964.

WILSON, A. The Common Concern: Controlling the Professionalization of Adult Education. Adult Education Quarterly, v. 44, n. 1, p. 1-16, 1993. 


\section{RESUMO}

Como em outros campos de trabalho, a profissionalização na educação de adultos está sendo afetado por rápidas mudanças sociopolíticas; diferentemente, porém, desmembrar o conceito de profissionalização na educação de adultos é mais complexo devido à própria amplidão do campo e às suas peculiaridades. Esta contribuição revê modelos tradicionais de profissionalismo através das lentes de uma perspectiva de 'profissionalismo funcional'. Ao fazê-lo, o principal argumento das autoras é que não é apropriado conceituar a educação de adultos como uma profissão ou um campo profissional tout court. Existem diversas ocupações no campo da educação de adultos que se posicionam ao longo de um continuum. Consequentemente, as autoras sugerem que a profissionalização entre os praticantes da educação de adultos deveria ser avaliada à luz do conhecimento sobre as teorias do aprendizado adulto que esses praticantes possuem, da epistemologia ética que guia o comportamento deles e do grau de confiança dos aprendizes adultos, mais que por uma visão restrita da ocupação específica que eles detém.

Palavras-chave: profissionalismo, profissionalização, educação de adultos, professores de adultos

\section{CONCEPTUALIZING PROFESSIONALISM AMONG TEACHERS OF ADULTS IN THE EUROPEAN CONTEXT}

\section{ABSTRACT}

Similarly to other occupational fields, professionalism in adult education is being affected by rapid sociopolitical changes; dissimilarly, however, unfolding the concept of professionalism in adult education is more complex due to the vastness of the field itself and its peculiar features. This contribution revisits traditional models of professionalism through the glasses of a 'role professionalism' perspective. In doing so, the authors' main argument is that it is not appropriate to conceptualise adult education as one profession or as one professional field tout court. There exist several occupations in the field of adult education that position themselves along a continuum. Consequently the authors suggest that professionalization among adult education practitioners should be assessed in light of the knowledge about adult learning theories practitioners possess, the ethical epistemology that guides their behaviour and the degree of trust by the adult learners, rather than a restrictive view on the specific occupation they hold.

Key words: professionalism, professionalisation, adult education, teachers of adults.

Submetido em Jan. 2016

Aprovado em Jun. 2016 